\title{
The Combined Effect of Hyperuricaemia and Overweight/Obesity on Risk of Hypertension in Adults

\author{
Z Li ${ }^{1}, \mathrm{~W}$ Qin ${ }^{1}, \mathrm{~L} \mathrm{Li}^{1}$, Q Wu${ }^{1}$, Y Wang ${ }^{2}$
}

\begin{abstract}
Background: While hyperuricaemia and overweight/obesity can act alone to increase the prevalence of hypertension, few studies have examined their combined effect.

Methods: This cross-sectional study of 42332 Han Chinese from southwestern China investigated the combined effect of hyperuricaemia and overweight/obesity on risk of hypertension in the entire sample as well as in different genders and age groups.

Results: Hypertension was significantly more prevalent among individuals with both hyperuricaemia and overweight/obesity (45.5\%) than among those with hyperuricaemia alone (28.1\%) or overweight/obesity alone (31.3\%). Similarly, the increase in hypertension risk in the presence of both hyperuricaemia and overweight/obesity $(O R=6.777,95 \%$ CI 6.133, 7.489) was significantly greater than the increase in the presence of hyperuricaemia alone $(O R=3.168,95 \%$ CI 2.705, 3.711) or overweight/obesity alone (OR $=3.693,95 \%$ CI 3.503, 3.893). These results were similar across each age group. The same trend was also observed when comparing men and women, though the odds ratios were greater for women.

Conclusion: Co-occurrence of hyperuricaemia and overweight/obesity increases risk of hypertension more than either morbidity on its own, and this risk differential is significantly greater in women than men. These findings should be confirmed in other ethnic groups and in longitudinal studies.
\end{abstract}

Keywords: Hypertension, hyperuricaemia, obesity, overweight, uric acid

WIMJ Open 2016; 3 (1): 10

\section{INTRODUCTION}

Essential or primary hypertension is estimated to cause more than half of the approximately 17 million deaths from cardiovascular disease that occur annually around the world (1). A systematic review found that in 2008, hypertension was present in approximately $40 \%$ of adults over 25 years old all over the world (1). This prevalence is increasing, particularly in developing countries (2).

Effective prevention and control of hypertension depend on understanding its risk factors (3). Uric acid, a metabolic product of purine oxidation in humans, is a risk factor in numerous cardiovascular, metabolic and renal diseases (4), and its association with hypertension has been known for nearly a century (5), with more recent studies clearly establishing a link between the two (6). Obesity is

From: ${ }^{1}$ West China School of Medicine and ${ }^{2}$ Health Management Center, West China Hospital, Sichuan University, Chengdu, Sichuan, China.

Correspondence: Dr Y Wang, Health Management Center, West China Hospital, Sichuan University, No. 37 Guo Xue Xiang, Chengdu 610041, Sichuan, China. E-mail: yjwang1963@sina.com another factor clearly linked to hypertension, and the global epidemic of overweight/obesity due to improvements in living conditions is helping to drive the increasing prevalence of hypertension (7).

Most studies on risk factors for hypertension have separated hyperuricaemia and overweight/obesity when examining their role in hypertension $(6,7)$. This raises the question of whether and how the two morbidities interact in affecting the risk of hypertension onset, progression to more serious cardiovascular disease and patient prognosis.

\section{SUBJECTS AND METHODS}

The study protocol was approved by the Ethics Committee of West China Hospital of Sichuan University, and written informed consent was obtained from all participants.

A consecutive sample of outpatients at the Health Management Center of West China Hospital of Sichuan University was recruited between January and August 2014. To be enrolled in the study, participants had to (a) already be registered in the centre, (b) not have severe kidney disease, 
and (c) have no other diseases which can influence the blood pressure significantly.

Demographic data were collected after conducting a complete physical examination, including gender, age, height, weight, blood pressure (after a 15-minute rest) and history of hypertension, drinking and smoking. Blood samples (12-hour fasting) were collected and analysed for levels of uric acid and creatinine level. Subjects were asked not to smoke or drink for the three days prior to the examination. All data were recorded by two researchers independently, following standardized procedures. In the event of discrepancies between the two data sets, the subject was re-examined and/or the archived blood sample was reanalysed.

A subject was classified as having hypertension if he or she had a systolic blood pressure (SBP) $\geq 140 \mathrm{mmHg}$ and/or diastolic blood pressure (DBP) $\geq 90 \mathrm{mmHg}$ during the physical examination (2) or if he or she had previously been diagnosed as hypertensive by healthcare professionals, regardless of whether they were taking antihypertensive medication at the time of the study.

A subject was defined as having hyperuricaemia if he or she had a serum urate level of $\geq 490 \mathrm{~mol} / \mathrm{L}$ (men) and $\geq 380 \mathrm{~mol} / \mathrm{L}$ (women). These thresholds are based on diagnostic criteria of the reagents in the Clinical Laboratory of West China Hospital. Overweight/obesity was defined as a body mass index (BMI) $\geq 24$ based on the recommendations of the China Obesity Task Force (8).

\section{Data analysis}

Data were entered into Microsoft Excel 2007 and analysed using SPSS 17.0 (IBM, Chicago, USA). Hypertension prevalence rates and odds ratios (ORs) quantifying risk of hypertension, together with associated 95\% confidence intervals (CIs), were calculated across all subjects and for different age and gender subgroups. Differences in hypertension prevalence were assessed for significance using the Chi-squared test. Using binary logistic regression, ORs were calculated to assess risk in the presence of hyperuricaemia and/or overweight/obesity; these ORs were always calculated with respect to risk in subjects lacking either condition.

\section{RESULTS}

During the study period, 43556 potentially eligible Han Chinese came into the outpatient Health Management Center. After excluding 1224 individuals (2.8\%) due to diseases that might affect blood pressure, such as severe kidney disease, we included 42332 individuals in the study (24 591 men; 17 731 women; age range, 18 to 98 years). Of this total, 23734 subjects (56\%) neither had hyperuricaemia nor were overweight/obese; 17772 (42\%) were overweight/obese, 8651 (20\%) had hypertension and 2678 (6\%) had hyperuricaemia. Based on data from the entire study population, hypertension was significantly more prevalent among adults with hyperuricaemia (40.2\%) than among those without hyperuricaemia $(19.1 \%, p<0.001$; Table 1$)$. The same was true of hypertension prevalence among those who were overweight/obese $(32.7 \%)$ and those who were not $(11.5 \%, p<0.001$; Table 2). Similar results were obtained when we performed subgroup analysis based on gender or age (20-39, 40-59 or $\geq 60$ years old)

Table 1: Prevalence of hypertension in outpatients from southwestern China, stratified by hyperuricaemia status, age and gender*

\begin{tabular}{llrrrr}
\hline \multirow{2}{*}{$\begin{array}{l}\text { Group or } \\
\text { subgroup }\end{array}$} & Age & \multicolumn{2}{c}{ No hyperuricaemia } & \multicolumn{2}{c}{ Hyperuricaemia } \\
\cline { 2 - 6 } & (year) & \multicolumn{2}{c}{$\begin{array}{c}\text { Hypertension } \\
\mathbf{n}\end{array}$} & $\mathbf{( \% )}$ & \multicolumn{2}{c}{$\begin{array}{c}\text { Hypertension } \\
\mathbf{n}\end{array}$} & $\mathbf{( \% )}$ \\
\hline All & & 7575 & 19.1 & 1076 & 40.2 \\
Male & $18-39$ & 720 & 8.4 & 138 & 19 \\
& $40-59$ & 2539 & 25.1 & 351 & 43.7 \\
& $\geq 60$ & 2125 & 52.1 & 216 & 68.1 \\
Female & $18-39$ & 103 & 1.3 & 9 & 4.6 \\
& $40-59$ & 982 & 13.8 & 112 & 38.5 \\
& $\geq 60$ & 1106 & 52.3 & 250 & 72.3 \\
\hline
\end{tabular}

${ }^{*} p$ in all cases was $<0.001$

Table 2: Prevalence of hypertension in outpatients from southwestern China, stratified by body mass index, age and gender*

\begin{tabular}{llrrrr}
\hline \multirow{2}{*}{$\begin{array}{l}\text { Group or } \\
\text { subgroup }\end{array}$} & Age & \multicolumn{3}{c}{ No obesity/overweight } & \multicolumn{2}{c}{ Obesity/overweight } \\
\cline { 2 - 6 } & (year) & \multicolumn{2}{c}{$\begin{array}{c}\text { Hypertension } \\
\text { n }\end{array}$} & $\mathbf{( \% )}$ & \multicolumn{2}{c}{$\begin{array}{c}\text { Hypertension } \\
\text { n }\end{array}$} & $\mathbf{( \% )}$ \\
\hline All & & 2831 & 11.5 & 5820 & 32.7 \\
Male & $18-39$ & 188 & 3.9 & 670 & 15.3 \\
& $40-59$ & 614 & 14.8 & 2276 & 33.6 \\
& $\geq 60$ & 895 & 24.2 & 1446 & 63.2 \\
Female & $18-39$ & 61 & 0.9 & 51 & 5.6 \\
& $40-59$ & 504 & 9.7 & 590 & 26.6 \\
& $\geq 60$ & 569 & 45.4 & 787 & 65.3 \\
\hline
\end{tabular}

* $p$ in all cases was $<0.001$

We also found that hyperuricaemia was significantly more prevalent among subjects who were overweight/obese $(10.5 \%)$ than among those who were not $(3.3 \%, p<0.001$; Table 3). Similar results were obtained for subgroup analysis

Table 3: Prevalence of hyperuricaemia by body mass index status*

\begin{tabular}{llccrr}
\hline \multirow{2}{*}{$\begin{array}{l}\text { Group or } \\
\text { subgroup }\end{array}$} & Age & No obesity/overweight & \multicolumn{2}{c}{ Obesity/overweight } \\
\cline { 2 - 6 } & (year) & \multicolumn{2}{c}{$\begin{array}{c}\text { Hyperuricaemia } \\
\text { n }\end{array}$} & $\begin{array}{r}\text { Hyperuricaemia } \\
\text { (\%) }\end{array}$ & \multicolumn{1}{c}{$\mathbf{\text { (\%) }}$} \\
\hline All & & 816 & 3.3 & 1862 & 10.5 \\
Male & $18-39$ & 184 & 3.8 & 543 & 12.4 \\
& $40-59$ & 159 & 3.8 & 644 & 9.5 \\
Female & $\geq 60$ & 106 & 5 & 211 & 9.2 \\
& $18-39$ & 128 & 1.8 & 66 & 7.3 \\
& $40-59$ & 119 & 2.3 & 172 & 7.8 \\
& $\geq 60$ & 120 & 9.6 & 226 & 18.8 \\
\hline
\end{tabular}

${ }^{*} p$ in all cases was $<0.001$ 
based on gender or age. In fact, the dual condition of overweight/obesity with hyperuricaemia $(69.5 \%)$ was significantly more prevalent among all subjects than overweight/obesity alone $(40.1 \%, p<0.001$; Table 4). Similar results were obtained for subgroup analysis based on gender or age.

Table 4: Prevalence of overweight/obesity by hyperuricaemia status*

\begin{tabular}{|c|c|c|c|c|c|}
\hline \multirow{3}{*}{$\begin{array}{l}\text { Group or } \\
\text { subgroup }\end{array}$} & \multirow{3}{*}{$\begin{array}{l}\text { Age } \\
\\
\text { (year) }\end{array}$} & \multicolumn{2}{|c|}{ No hyperuricaemia } & \multicolumn{2}{|c|}{ Hyperuricaemia } \\
\hline & & \multicolumn{2}{|c|}{$\begin{array}{l}\text { Overweight/ } \\
\text { obesity }\end{array}$} & \multicolumn{2}{|c|}{$\begin{array}{c}\text { Overweight/ } \\
\text { obesity }\end{array}$} \\
\hline & & $\mathbf{n}$ & $(\%)$ & $\mathbf{n}$ & $(\%)$ \\
\hline \multirow[t]{4}{*}{ All } & & 15910 & 40.1 & 1862 & 69.5 \\
\hline & $18-39$ & 3836 & 45 & 543 & 74.7 \\
\hline & $40-59$ & 6132 & 60.5 & 644 & 80.2 \\
\hline & $\geq 60$ & 2077 & 50.9 & 211 & 66.6 \\
\hline \multirow[t]{3}{*}{ Female } & $18-39$ & 839 & 10.9 & 66 & 34 \\
\hline & $40-59$ & 2047 & 28.8 & 172 & 59.1 \\
\hline & $\geq 60$ & 979 & 46.3 & 226 & 65.3 \\
\hline
\end{tabular}

${ }^{*} p$ in all cases was $<0.001$

Finally, we observed that hypertension was significantly more prevalent among adults with both hyperuricaemia and overweight/obesity (45.5\%) than among those with hyperuricaemia alone $(28.1 \%, p<0.001)$ or overweight/obesity alone $(31.3 \%, p<0.001$; Table 5$)$. All these prevalence rates were significantly higher than the rate of hypertension in individuals who neither had hyperuricaemia nor were overweight/obese $(11 \%, p<0.001)$. Similar results were obtained with subgroups based on gender or age.
To quantify the association of risk of hypertension with hyperuricaemia, overweight/obesity and the two conditions together, we generated a logistic regression model to calculate ORs and 95\% CIs. Odds ratios indicating the risk of hypertension in the presence of hyperuricaemia and/or overweight/obesity were calculated with respect to risk in subjects lacking either condition. The risk of hypertension was significantly higher in the presence of both hyperuricaemia and overweight/obesity (OR 6.777, 95\%CI 6.133, 7.489) than in the presence of hyperuricaemia alone (OR $3.168,95 \%$ CI $2.705,3.711$ ) or overweight/obesity alone (OR 3.693, 95\%CI 3.503, 3.893; Table 6). These calculations were then repeated for sub-groups based on gender and age. In all cases, OR was greater in the presence of both hyperuricaemia and overweight/ obesity than in the presence of either morbidity alone; ORs in the presence of both or single morbidities were greater for women than men. In nearly all cases, ORs in the presence of overweight/obesity alone or the combination of hyper-uricaemia and overweight/obesity decreased progressively with age. The exception was ORs in the presence of hyperuricaemia, which peaked in the age group 40-59 years for both men and women.

\section{DISCUSSION}

In this large cross-sectional study in southwestern China, we found that hyperuricaemia and overweight/obesity, both known to increase risk of hypertension on their own, interact to increase the risk substantially. These findings, which are consistent with a large study in the United States of America (5), argue for the need for more extensive monitoring of

Table 5: Separate and combined effects on the prevalence of hypertension*

\begin{tabular}{|c|c|c|c|c|c|c|c|c|c|}
\hline \multirow{3}{*}{$\begin{array}{l}\text { Group or } \\
\text { subgroup }\end{array}$} & \multirow{3}{*}{$\begin{array}{l}\text { Age } \\
\text { (year) }\end{array}$} & \multicolumn{2}{|c|}{$\begin{array}{c}\text { No hyperuricaemia } \\
\text { No obesity/overweight }\end{array}$} & \multicolumn{2}{|c|}{$\begin{array}{l}\text { Hyperuricaemia } \\
\text { No obesity/overweight }\end{array}$} & \multicolumn{2}{|c|}{$\begin{array}{l}\text { No hyperuricaemia } \\
\text { Obesity/overweight }\end{array}$} & \multicolumn{2}{|c|}{$\begin{array}{l}\text { Hyperuricaemia } \\
\text { Obesity/overweigh }\end{array}$} \\
\hline & & \multicolumn{2}{|c|}{ Hypertension } & \multicolumn{2}{|c|}{ Hypertension } & \multicolumn{2}{|c|}{ Hypertension } & \multicolumn{2}{|c|}{ Hypertension } \\
\hline & & n & $(\%)$ & n & $(\%)$ & n & $(\%)$ & n & $(\%)$ \\
\hline All & & 2602 & 11 & 229 & 28.1 & 4973 & 31.3 & 847 & 45.5 \\
\hline Male & & 1577 & 17.4 & 120 & 26.7 & 3807 & 31.6 & 585 & 41.8 \\
\hline \multirow[t]{4}{*}{ Female } & & 1025 & 7.9 & 109 & 29.7 & 1166 & 30.2 & 262 & 56.5 \\
\hline & $18-39$ & 233 & 2 & 16 & 5.1 & 590 & 12.6 & 131 & 21.5 \\
\hline & $40-59$ & 1034 & 11.4 & 84 & 30.2 & 2487 & 30.4 & 379 & 46.4 \\
\hline & $\geq 60$ & 1335 & 42.6 & 129 & 57.1 & 1896 & 62 & 337 & 77.1 \\
\hline \multirow[t]{3}{*}{ Male } & $18-39$ & 176 & 3.7 & 12 & 6.5 & 544 & 14.2 & 126 & 23.2 \\
\hline & $40-59$ & 569 & 14.2 & 45 & 28.3 & 1970 & 32.1 & 306 & 47.5 \\
\hline & $\geq 60$ & 832 & 41.5 & 63 & 59.4 & 1293 & 62.3 & 153 & 72.5 \\
\hline \multirow[t]{3}{*}{ Female } & $18-39$ & 57 & 0.8 & 4 & 3.3 & 46 & 5.5 & 5 & 7.6 \\
\hline & $40-59$ & 465 & 9.2 & 39 & 32.8 & 517 & 25.3 & 73 & 42.4 \\
\hline & $\geq 60$ & 503 & 44.4 & 66 & 55 & 603 & 61.6 & 184 & 81.4 \\
\hline
\end{tabular}

$* p$ in all cases was $<0.001$ 
Table 6: Separate and combined effects of overweight/obesity and hyperuricaemia on risk of hypertension in outpatients from southwestern China, stratified by age and gender

\begin{tabular}{|c|c|c|c|c|c|c|c|c|c|c|c|c|}
\hline \multirow[t]{2}{*}{$\begin{array}{l}\text { Group or } \\
\text { subgroup }\end{array}$} & \multirow{2}{*}{$\begin{array}{l}\text { Age } \\
\text { (year) }\end{array}$} & \multicolumn{2}{|c|}{$\begin{array}{c}\text { No hyperuricaemia } \\
\text { No obesity/overweight }\end{array}$} & \multicolumn{3}{|c|}{$\begin{array}{c}\text { Hyperuricaemia } \\
\text { No obesity/overweight }\end{array}$} & \multicolumn{3}{|c|}{$\begin{array}{l}\text { Obesity/overweight } \\
\text { No hyperuricaemia }\end{array}$} & \multicolumn{3}{|c|}{$\begin{array}{r}\text { Hyperuricaemia } \\
\text { Obesity/overweight }\end{array}$} \\
\hline & & $\mathbf{n}$ & OR & $\mathbf{n}$ & OR & $95 \% \mathrm{CI}$ & $\mathbf{n}$ & OR & $95 \% \mathrm{CI}$ & $\mathbf{n}$ & OR & $95 \% \mathrm{CI}$ \\
\hline All & & 2602 & 1 & 229 & 3.2 & $2.705,3.711$ & 4973 & 4 & $3.503,3.893$ & 847 & 7 & $6.133,7.489$ \\
\hline Male & & 1577 & 1 & 120 & 2.1 & $1.7,2.618$ & 3807 & 3 & $2.503,2.855$ & 585 & 4 & $3.695,4.688$ \\
\hline \multirow[t]{4}{*}{ Female } & & 1025 & 1 & 109 & 5 & $3.922,6.248$ & 1166 & 5 & $4.609,5.559$ & 262 & 15 & $12.514,18.456$ \\
\hline & $18-39$ & 233 & 1 & 16 & 2.6 & $1.559,4.407$ & 590 & 7 & $5.993,8.184$ & 131 & 13 & $10.529,16.772$ \\
\hline & $40-59$ & 1034 & 1 & 84 & 3.4 & $2.583,4.380$ & 2487 & 3 & $3.133,3.677$ & 379 & 7 & $5.787,7.843$ \\
\hline & $\geq 60$ & 1335 & 1 & 129 & 1.8 & $1.367,2.358$ & 1896 & 2 & $1.993,2.442$ & 337 & 5 & $3.599,5.749$ \\
\hline \multirow[t]{3}{*}{ Male } & $18-39$ & 176 & 1 & 12 & 1.8 & $0.979,3.278$ & 544 & 4 & $3.559,5.058$ & 126 & 8 & $6.044,9.959$ \\
\hline & $40-59$ & 569 & 1 & 45 & 2.4 & $1.667,3.400$ & 1970 & 3 & $2.574,3.167$ & 306 & 5 & $4.569,6.526$ \\
\hline & $\geq 60$ & 832 & 1 & 63 & 2.1 & $1.385,3.069$ & 1293 & 2 & $2.047,2.632$ & 153 & 4 & $2.709,5.088$ \\
\hline \multirow{3}{*}{ Female } & $18-39$ & 57 & 1 & 4 & 3.8 & $1.371,10.738$ & 46 & 7 & $4.646,10.244$ & 5 & 9 & $3.777,25.163$ \\
\hline & $40-59$ & 465 & 1 & 39 & 4.8 & $3.251,7.155$ & 517 & 3 & $2.912,3.837$ & 73 & 7 & $5.312,10.016$ \\
\hline & $\geq 60$ & 503 & 1 & 66 & 1.5 & $1.050,2.238$ & 603 & 2 & $1.690,2.394$ & 184 & 5 & $3.853,7.838$ \\
\hline
\end{tabular}

CI: confidence interval; OR: odds ratio

hyperuricaemia in populations known to be at risk of hypertension and for public health interventions that take into account the inordinate threat posed by hyperuricaemia and overweight together.

Our results provide large-scale confirmation that hyperuricaemia is associated with hypertension, which may occur by several mechanisms. One is that hyperuricaemia induces vascular endothelial injury (9) which can reduce blood vessel elasticity and cause hypertension. A second mechanism is that hyperuricaemia can cause glomerular artery damage (10) that renders renal tubules sensitive to salt, leading to sodium and water retention that results in high blood pressure (11). Third, uric acid has been shown to stimulate the renin-angiotensin-aldosterone system directly to increase blood pressure (12). In animals with uric acidassociated hypertension, treating the hyperuricaemia early can bring blood pressure under control $(10,13)$. In humans with hyperuricaemia-associated hypertension, double-blind experiments show that urate-lowering drugs can lower blood pressure $(14,15)$.

In overweight and obese individuals, visceral adipose tissue releases free fatty acids into the circulation, which upregulate hepatic gluconeogenesis; this reduces glucose uptake into peripheral tissues, resulting in hyperinsulinaemia. This leads in turn to salt retention in the kidney, raising blood pressure (16). In addition to hyperinsulinaemia and activation of the renin-angiotensin-aldosterone system in adipose tissue, a recent study suggests that vascular stiffness is also a risk factor in obesity-associated hypertension (17).

The finding in this study that individuals with both hyperuricaemia and overweight/obesity are at significantly higher risk of hypertension than individuals with either morbidity alone brings together several disparate results in the literature. Hyperuricaemia reduces skeletal muscle glucose uptake (18-20) which can cause hyperglycaemia. At the same time, elevated levels of uric acid in fat cells can lead to insulin resistance, leading to hyperglycaemia as well as hyperinsulinaemia due to compensatory production of insulin by the pancreas (21). Simultaneous presence of hyperglycaemia and hyperinsulinaemia, as well as obesity, is a hallmark of metabolic syndrome. Hyperinsulinaemia then increases uric acid reabsorption by renal tubules, leading to hyperuricaemia (22), thereby creating a vicious cycle. Consistent with these results, we found that individuals who were overweight/obese were more likely to be hyperuricaemic than those who were not overweight/obese and vice versa. These findings suggest that clinicians, epidemiologists and public health practitioners should be aware of the dangerous interaction between hyperuricaemia and obesity, particularly in vulnerable populations such as those with metabolic syndrome.

In our study population, women were at much higher risk of hypertension than men in the presence of one or both morbidities, particularly women aged 40-59 years. Future research should examine these gender-specific effects, and public health interventions should take them into account.

The main advantages of our study are that it involves a large sample from a medical centre that draws patients from a large geographical area in southwestern China, and it is one of the few studies to focus on the interaction between hyperuricaemia and overweight/obesity in influencing the risk of hypertension. Nevertheless, the study has significant limitations: its cross-sectional design, which prevents assessment of causal relationships, the fact that all data came from a single medical centre and were primarily from Han Chinese, and failure to take into account other factors affecting risk of hypertension, such as smoking history, drinking history, diet, stress at home or on the job and family history of hypertension. Future large studies are needed that take into account as many of these factors as possible in other ethnic populations. 


\section{CONCLUSION}

While hyperuricaemia and overweight/obesity are independent risk factors for hypertension, they increase risk to a much greater extent when present together. Women are more vulnerable to hypertension than men in the presence of one or both morbidities. These findings, if verified in other ethnic groups, should help guide public health interventions and hypertension treatment programmes to ensure that all relevant risk factors are controlled.

\section{REFERENCES}

1. Lim SS, Vos T, Flaxman AD, Danaei G, Shibuya K, Adair-Rohani H et al. A comparative risk assessment of burden of disease and injury attributable to 67 risk factors and risk factor clusters in 21 regions, 1990-2010: a systematic analysis for the Global Burden of Disease Study 2010. Lancet 2013; 380: 2224-60.

2. Whitworth JA; World Health Organization, International Society of Hypertension Writing Group. 2003 World Health Organization (WHO)/International Society of Hypertension (ISH) statement on management of hypertension. J Hypertens 2003; 21: 1983-92.

3. Chockalingam A, Campbell NR, Fodor JG. Worldwide epidemic of hypertension. Can J Cardiol 2006; 22: 553-5.

4. Gustafsson D, Unwin R. The pathophysiology of hyperuricaemia and its possible relationship to cardiovascular disease, morbidity and mortality. BMC Nephrol 2013; 14: 164.

5. Han G, Gonzalez S, DeVries D. Combined effect of hyperuricemia and overweight/obesity on the prevalence of hypertension among US adults: result from the National Health and Nutrition Examination Survey. J Hum Hypertens 2014; 28: 579-86. doi: 10.1038/jhh.2014.31. Epub 2014 May 1.

6. Ofori SN, Odia OJ. Serum uric acid and target organ damage in essential hypertension. Vascular Health Risk Manag 2014; 10: 253

7. Rahmouni K, Correia ML, Haynes WG, Mark AL. Obesity-associated hypertension: new insights into mechanisms. Hypertension 2005; 45: 9-14.

8. Zhou B; Coorperative Meta-Analysis Group Of China Obesity Task Force. [Predictive values of body mass index and waist circumference to risk factors of related diseases in Chinese adult population]. Zhonghua Liu Xing Bing Xue Za Zhi 2002; 23: 5-10. In Chinese

9. Kang D-H, Nakagawa T. Uric acid and chronic renal disease: possible implication of hyperuricemia on progression of renal disease. Semin Nephrol 2005; 25: 43-9

10. Mazzali M, Kanellis J, Han L, Feng L, Xia YY, Chen Q et al. Hyperuricemia induces a primary renal arteriolopathy in rats by a blood pressure-independent mechanism. Am J Physiol Renal Physiol 2002; 282: F991-7.
11. Watanabe S, Kang D-H, Feng L, Nakagawa T, Kanellis J, Lan H et al. Uric acid, hominoid evolution, and the pathogenesis of salt-sensitivity. Hypertension 2002; 40: 355-60.

12. Mene P, Punzo G. Uric acid: bystander or culprit in hypertension and progressive renal disease? J Hypertens 2008; 26: 2085-92.

13. Mazzali M, Hughes J, Kim Y-G, Jefferson JA, Kang D-H, Gordon K-L et al. Elevated uric acid increases blood pressure in the rat by a novel crystal-independent mechanism. Hypertension 2001; 38: 1101-6.

14. Soletsky B, Feig DI. Uric acid reduction rectifies prehypertension in obese adolescents. Hypertension 2012; 112: 1969-80.

15. Feig DI, Soletsky B, Johnson RJ. Effect of allopurinol on blood pressure of adolescents with newly diagnosed essential hypertension: a randomized trial. JAMA 2008; 300: 924-32.

16. Johnson RJ, Kang D-H, Feig D, Kivlighn S, Kanellis J, Watanabe S et al. Is there a pathogenetic role for uric acid in hypertension and cardiovascular and renal disease? Hypertension 2003; 41: 1183-90.

17. Kang YS. Obesity associated hypertension: new insights into mechanism. Electrolytes Blood Press 2013; 11: 46-52. doi: 10.5049/EBP.2013.11.2.46. Epub 2013 Dec 31.

18. Feig DI, Kang DH, Johnson RJ. Uric acid and cardiovascular risk. New Engl J Med 2008; 359: 1811-21. doi: 10.1056/NEJMra0800885.

19. So A, Thorens B. Uric acid transport and disease. J Clin Invest 2010; 120: $1791-9$.

20. Kanellis J, Kang DH. Uric acid as a mediator of endothelial dysfunction, inflammation, and vascular disease. Semin Nephrol 2005; 25: $39-42$.

21. Facchini F, Chen YD, Hollenbeck CB, Reaven GM. Relationship between resistance to insulin-mediated glucose uptake, urinary uric acid clearance, and plasma uric acid concentration. JAMA 1991; 266: 3008 11.

22. Quiñones Galvan A, Natali A, Baldi S, Frascerra S, Sanna G, Ciociaro $\mathrm{D}$ et al. Effect of insulin on uric acid excretion in humans. Am J Physiol 1995; 268: E1-5.

Received 03 Jun 2015

Accepted 12 Jun 2015

Published 08 Feb 2016

Online: http://www.mona.uwi.edu/wimjopen/article/1661

(C) Li et al 2016.

This is an open access article made freely available under Creative Commons Attribution 4.0 International (CC BY 4.0). Users are free to share, copy and adapt this work as long as the copyright holder (author) is appropriately and correctly credited. See http://creativecommons.org/ licences/by/4.0/deed.en_us for more information. 